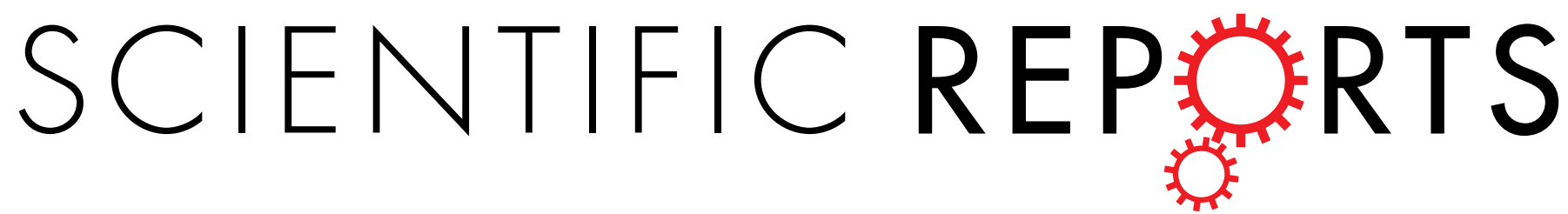

\title{
Erratum: Digital Ecology: Coexistence and Domination among Interacting Networks
}

Kaj-Kolja Kleineberg \& Marián Boguñá

Scientific Reports 5:10268; doi: 10.1038/srep10268; published online 19 May 2015; updated on 30 July 2015

This Article contains a typographical error in Equation (7).

$$
\omega_{i}\left(\boldsymbol{\rho}^{a}\right)=\frac{\psi\left(\rho_{i}{ }^{a}\right)}{\sum_{j=1}^{n_{l}} \psi\left(\rho_{i}^{a}\right)},
$$

should read:

$$
\omega_{i}\left(\boldsymbol{\rho}^{a}\right)=\frac{\psi\left(\rho_{i}^{a}\right)}{\sum_{j=1}^{n_{l}} \psi\left(\rho_{j}^{a}\right)},
$$

